\title{
Reply I: An assessment of the preconceptional mitochondrial hypothesis
}

\author{
M Sanderson ${ }^{*, \mathbf{I}}, \mathbf{X O} \mathbf{S h u}^{\mathbf{2}}$ and W Zheng
' University of Texas, Houston School of Public Health at Brownsville, Brownsville, TX 78520, USA; ${ }^{2}$ Center for Health Services Research and
Vanderbilt-Ingram Cancer Center, Vanderbilt University, Nashville, TN 37232-8300, USA
}

British Journal of Cancer (2003) 88, 1819 - I82I. doi:I0.1038/sj.bjc.6600980 www.bjcancer.com

(c) 2003 Cancer Research UK

Sir,

We found Dr van Noord's preconceptional mitochondrial hypothesis interesting particularly in line with a recent report linking polymorphisms of two DNA base excision repair genes (XRCC1 and hOGG1) to breast cancer risk in daughters born to older mothers (Hodgson et al, 2003). Manganese superoxide dismutase (MnSOD) may impair the mitochondria's ability to reduce oxidative stress (Oberley and Oberley, 1997). MnSOD has been linked to breast cancer (Ambrosone et al, 1999), and may be another pathway through which older maternal age may function. Further support for this hypothesis comes from a recent study that found mitochondrial DNA damage in breast cancer tissue (Richard et al, 2000).

To test this hypothesis, we analysed the association of parental age with breast cancer risk using data from the Shanghai Breast Cancer Study (SBCS), and the results are in shown Table 1. After adjustment for established breast cancer risk factors and pregnancy order, we did not find an association between older maternal or paternal age and premenopausal breast cancer in our low-risk population. Additional adjustment for paternal age resulted in a nonsignificantly elevated risk of breast cancer associated with older maternal age. All perinatal information was based on maternal report.

Although we collected information on whether the mother had a threatened miscarriage with the index pregnancy, too few women reported this adverse event (six case mothers, 13 control mothers) to provide a stable risk estimate. Other studies may have sufficient numbers of mothers to investigate this aspect of Dr van Noord's hypothesis.

Dr van Noord argued that insulin-like growth factor- I (IGF-1) might be unlikely to explain the inconsistent findings on birth weight and breast cancer risk in the literature, since the link between IGF-I and breast cancer risk has been found primarily in premenopausal women, while the high birth weight-breast cancer association has been seen among pre- and postmenopausal women. A previous report from the SBCS showed that elevated levels of IGF-I were associated with an increased risk of breast cancer among all women, but the association was more pronounced among women diagnosed premenopausally and among women with a high body mass index or waist-to-hip ratio (Yu et al, 2001). We found in a large US study that high birth

Table I Odds ratios of breast cancer associated with maternal age and paternal age

\begin{tabular}{|c|c|c|c|c|c|c|}
\hline & Cases $(n=288)$ & Controls $(n=350)$ & $\mathbf{O R}^{\mathrm{a}}$ & $(95 \% \mathrm{Cl})$ & $\mathbf{O R}^{\mathbf{b}}$ & $(95 \% \mathrm{Cl})$ \\
\hline \multicolumn{7}{|c|}{ Maternal age (years) } \\
\hline$<25$ & 73 & 98 & 1.0 & (referent) & 1.0 & (referent) \\
\hline $25-29$ & 123 & 127 & 1.4 & $(0.8-2.3)$ & 1.6 & $(0.9-2.7)$ \\
\hline $30-34$ & 63 & 77 & 1.1 & $(0.6-2.0)$ & 1.5 & $(0.8-2.9)$ \\
\hline$\geqslant 35$ & 29 & 47 & 1.1 & $(0.5-2.2)$ & 1.6 & $(0.7-3.9)$ \\
\hline$P$ trend & & & $P=0.84$ & & $P=0.34$ & \\
\hline \multicolumn{7}{|c|}{ Paternal age (years) } \\
\hline$<25$ & 34 & 41 & 1.0 & (referent) & 1.0 & (referent) \\
\hline $25-29$ & 96 & 94 & 1.4 & $(0.7-2.8)$ & 1.3 & $(0.6-2.7)$ \\
\hline $30-34$ & 88 & 103 & 1.3 & $(0.7-2.7)$ & 1.2 & $(0.6-2.6)$ \\
\hline$\geqslant 35$ & 70 & 111 & 0.9 & $(0.4-1.9)$ & 0.7 & $(0.3-1.8)$ \\
\hline$P$ trend & & & $P=0.13$ & & $P=0.08$ & \\
\hline
\end{tabular}

${ }^{a}$ Adjusted for age, income, family history of breast cancer in first-degree relative, history of fibroadenoma, age at menarche parity, age at first live birth, and pregnancy order. ${ }^{b}$ Adjusted for age, income, family history of breast cancer in first-degree relative, history of fibroadenoma, age at menarche, parity, age at first live birth, pregnancy order, and maternal age or paternal age. 
weight was associated with an elevated risk among premenopausal women $(\mathrm{OR}=1.7,95 \%$ CI 1.1-2.5), but a nonsignificantly reduced risk among postmenopausal women $(\mathrm{OR}=0.6,95 \% \mathrm{CI}$
$0.3-1.1$ ) (Sanderson et al, 1996). Therefore, IGF-I as a potential explanation for the birth weight-breast cancer relationship cannot be ruled out.

\title{
REFERENCES
}

Ambrosone CB, Freudenheim JL, Thompson PA, Bowman E, Vena JE, Marshall JR, Graham S, Laughlin R, Nemoto T, Shields PG (1999) Manganese superoxide dismutase (MnSOD) genetic polymorphisms, dietary antioxidants, and risk of breast cancer. Cancer Res 59: 602-606 Hodgson ME, Worley K, Winkel S, Tse CK, Eaton A, Harlan B, Millikan RC (2003) Maternal age, polymorphisms in two DNA repair genes and breast cancer in the Carolina Breast Cancer Study. Presented at the Research Molecular and Genetic Epidemiology of Cancer American Association for Cancer International Conference, Waikoloa, HI, January, 2003

Oberley TD, Oberley LW (1997) Antioxidant enzyme levels in cancer. Histol Histopathol 12: 525 - 535
Richard SM, Bailliet G, Paez GL, Bianchi MS, Peltomaki P, Bianchi NO (2000) Nuclear and mitochondrial genome instability in human breast cancer. Cancer Res 60: 4231-4237

Sanderson M, Williams MA, Malone KE, Stanford JL, Emanuel I, White E, Daling JR (1996) Perinatal factors and risk of breast cancer. Epidemiology $7: 34-37$

Yu H, Jin F, Shu XO, Li BD, Dai Q, Cheng JR, Berkel HR, Zheng W (2002) Insulin like growth factors and breast cancer risk in Chinese women. Cancer Epidemiol Biomark Prev 11: 705-712

\section{Reply 2: Birth weight as a predictor of breast cancer: a case-control study in Norway}

\author{
LJ Vatten ${ }^{*, 1}$ and TIL Nilsen ${ }^{1,2}$ \\ 'Department of Community Medicine and General Practice, Nonwegian University of Science and Technology, Medical Research Center, N-7489 \\ Trondheim, Norway; ${ }^{2}$ The Norwegian Cancer Society, PO Box 5327 Majorstua, N-0304 Oslo, Norway
}

British Journal of Cancer (2003) 88, 1820 - I821. doi:I0.1038/sj.bjc.6600979 www.bjcancer.com

(c) 2003 Cancer Research UK

Sir,

We welcome the comments of van Noord concerning the different results for birth weight and breast cancer risk reported by ourselves (Vatten et al, 2002) and Sanderson et al (2002). He suggests that women's breast cancer risk is influenced by the preconception viability of their mothers' oocytes, particularly the quality of their mitochondria, since mitochondrial quality declines with age. Therefore, van Noord proposes that maternal age at birth is positively associated with breast cancer risk, suggesting that we reanalyse our data to test this hypothesis.

Reliable information on maternal age at birth was available in the Trondheim data, and hence this analysis is based on 186 breast cancer cases and 662 age-matched controls. We used conditional logistic regression to explore the association between the risk of breast cancer and maternal age at birth, and the estimated odds ratios are adjusted for age at first birth and parity. As shown in Table 1, we found no association with breast cancer risk over the four categories of maternal age at birth.

Although van Noord has proposed an interesting hypothesis, we found no evidence to support that maternal age at birth is positively associated with breast cancer risk. In light of our original findings, that both birth weight and birth length are positively associated with breast cancer risk, important mechanisms linking birth characteristics to breast cancer may be related to
Table I Odds ratios (ORs) and 95\% confidence intervals (Cls) of breast cancer associated with maternal age at birth

\begin{tabular}{lcccc}
\hline Variable & $\begin{array}{c}\text { Case } \\
\text { patients }\end{array}$ & $\begin{array}{l}\text { Control } \\
\text { subjects }\end{array}$ & OR $^{\mathbf{a b}}$ & $\mathbf{9 5 \%} \mathbf{~ C l}$ \\
\hline $\begin{array}{l}\text { Matemal age at birth } \\
\quad 25\end{array}$ & 56 & 196 & 1.0 & Reference \\
$25-29$ & 60 & 212 & 1.0 & $0.7-1.5$ \\
$30-34$ & 41 & 155 & 1.0 & $0.6-1.5$ \\
$\geqslant 35$ & 29 & 99 & 1.0 & $1.6-1.6$ \\
& & & $P$ trend $=0.97$ & \\
\hline
\end{tabular}

${ }^{a}$ ORs are computed using conditional logistic regression with cases and controls matched on year of birth. ${ }^{b}$ ORs are adjusted for age at first birth and parity in the regression model.

foetal growth. Recent research has shown that both birth weight and maternal pre-eclampsia are associated with adolescent growth and maturation (Vatten et al, 2003), and therefore, the intrauterine environment may initiate a tracking pattern of growth that ranges throughout childhood and adolescence. Ultimately, this may play a critical role in the development of breast cancer. 